\title{
Caracterização econômica dos municípios goianos segundo valor adicionado dos setores de atividade
}

\author{
Eduiges Romanatto* \\ Evelyn de Castro Cruvinel ${ }^{* *}$ \\ Eduardo Santos Araújo ${ }^{* * *}$ \\ Clécia Rosa Ivânia Satel ${ }^{* * * *}$
}

Resumo: O trabalho tem por objetivo caracterizar ou atribuir um perfil econômico aos municípios do estado de Goiás conforme suas atividades econômicas. Toma-se por base o Valor Adicionado (VA) por setor de atividade de cada município e seus respectivos pesos nos VAs específicos no município, bem como no Estado. Para caracterização foram utilizadas técnicas estatísticas multivariadas, mais especificamente análise fatorial e de agrupamentos. Os dados utilizados foram os do Produto Interno Bruto Municipal de 2011. Como resultado principal verificou-se a concentração da produção e da renda em poucos municípios do estado, bem como a forte dependência da maioria dos municípios goianos $(78,5 \%)$ da atividade de agropecuária e da administração pública.

Palavras-Chave: Valor adicionado. PIB municipal. Análise fatorial. Análise de agrupamentos.

\section{Economic characterization of Goiás municipalities according to added value of activity sectors}

Abstract: This paper aims to characterize the municipalities of Goiás as their economic activities taking as base the added value (VA) per sector and their respective weights in specific VA's of the municipality as well as State. For this, we used multivariate statistical techniques, specifically factor analysis and clustering. The data used were the Municipal Gross Domestic Product of 2011. As a main result it was found the concentration of production and income in a few municipalities of the State, as well as the strong dependence of most municipalities of Goiás in agriculture and services activity (with and without public administration).

Keywords: Added value. Municipal GDP. Factor analysis. Cluster analysis.

Classificação JEL: R1.

\section{Introdução}

O estado de Goiás vem passando por profundas transformações em sua economia, seja no setor agropecuário, pela modernização agrícola, que passou a integrar com outros setores da economia, levando à formação dos complexos agroindustriais, cujo desenvolvimento se

\footnotetext{
Gerente de Estatísticas Socioeconômicas no Instituto Mauro Borges Segplan-GO e Mestre em Desenvolvimento Econômico pela UFPR. E-mail: tgromanatto@yahoo.com.br.

** Pesquisadora no Instituto Mauro Borges, Segplan-GO. E-mail: evelyncruvinel@gmail.com.

*** Pesquisador no Instituto Mauro Borges, Segplan-GO e Mestre em Desenvolvimento Econômico pela UFPR. E-mail: edusanar@gmail.com.

**** Pesquisadora no Instituto Mauro Borges, Segplan-GO e Mestre em Economia Regional pela UEL. E-mail: clecia.satel@hotmail.com.
} 
deu por meio da integração entre a agropecuária moderna e o avanço da agroindústria, bem como a emergência de novas atividades industriais atraídas pelas políticas de incentivos fiscais, praticado por Goiás, a partir de meados da década de 1980 (ARRIEL, 2010). Estas transformações na economia goiana são evidenciadas no indicador do Produto Interno Bruto (PIB), onde Goiás tem apresentado ganhos de participação no fluxo de produção nacional nos últimos anos. Goiás representava $2 \%$ do PIB brasileiro em 1995, e evoluiu para 2,7\% em 2011, última estatística consolidada. Em termos de crescimento real, o PIB goiano tem crescido a um ritmo superior à média do país. Nos anos 2000, Goiás teve um crescimento médio anual de cerca de 5\%, contra $4 \%$ do Brasil.

Além dos incentivos fiscais, também contribuíram alguns planos de desenvolvimento implantados em Goiás. Dentre eles, o Programa de Desenvolvimento dos Cerrados Polocentro (1975); o Programa de Desenvolvimento da Região Geoeconômica de Brasília (1979); o Programa de Cooperação Nipo-Brasileira de Desenvolvimento dos Cerrados Prodecer (1985), e a instituição do Fundo Constitucional de Financiamento do Centro-Oeste (FCO) em 1989 (PIRES E RAMOS, 2009). Para ações visando incentivos fiscais, teve o Fundo de Fomento à Industrialização do Estado de Goiás (Fomentar), instituído em 1984 e substituído pelo Programa de Desenvolvimento Industrial de Goiás (Produzir), em 2000 (PASCHOAL, 2009).

Esses planos de desenvolvimento e de incentivos fiscais buscavam atrair atividades industriais, principalmente alimentícias, com o objetivo de gerar oportunidades ao estado de Goiás e aproveitar a agropecuária moderna, concentrada na produção de grãos e pecuária de corte que contava e ainda conta com altos níveis de produtividade.

Assim, com alguns programas de desenvolvimento e outros de incentivos fiscais, a economia goiana cresceu e aumentou sua participação no cenário nacional. Ainda, de acordo com Oliveira et. al (2010) e para dados de fluxo de comércio para 2009, Goiás mostra-se bastante integrado à economia nacional, sobretudo àqueles estados da região centro-sul, de onde vêm $39,8 \%$ do total das compras estaduais e se destinam $43,8 \%$ das vendas.

$\mathrm{Na}$ esteira da economia estadual, também ocorreu o crescimento e diversificação das atividades econômicas dos municípios goianos. Assim, busca-se compreender o perfil econômico destes, além de constatar qual atividade econômica (agropecuária, indústria ou serviços) responde pela maior geração de Valor Adicionado (VA) local, ou mesmo de sua importância no estado de Goiás. Entender o perfil econômico dos 246 municípios existentes no estado é fundamental para os formuladores de políticas públicas, de incentivos e fortalecimento da economia estadual. 
Assim, o objetivo do presente artigo é caracterizar ou atribuir um perfil econômico aos municípios do estado de Goiás conforme suas atividades econômicas, tomando-se como base o Valor Adicionado (VA) por setor de atividade de cada município e suas respectivas participações nos VAs do município e do estado, utilizando-se de metodologias de estatísticas multivariadas.

Para caracterizar os municípios conforme o seu perfil produtivo, utilizou-se de técnicas de estatística multivariada, mais especificamente análise de fatores e de clusters ou agrupamento. Para isso foram utilizados os dados do Produto Interno Bruto Municipal - PIB Municipal - para 2011, última divulgação oficial.

Este trabalho está dividido da seguinte maneira, além desta introdução: a seção 2 traz um breve histórico da economia goiana; a seção 3 o referencial teórico; na quarta estão informações sobre os dados e a metodologia; a quinta resultado e discussões e a sexta conclui o trabalho.

\section{Breve histórico da economia goiana}

No período de 1930-45, segundo Estevam (2004), a região centro-oeste atraiu fluxos expressivos de trabalhadores que foram expulsos de seus locais de origem em busca de uma ocupação no processo produtivo. Em Goiás, a maior parte da população se concentrava nos municípios situados ao longo da ferrovia que liga o Triângulo Mineiro a Anápolis e a atividade econômica era, basicamente, de subsistência. No entanto, após a instalação da Colônia Agrícola Ceres, o Estado passa a receber grandes fluxos de pessoas, o que contribuiu para o aumento da produção de grãos como arroz, milho e feijão.

A construção da nova capital de Goiás (Goiânia), que ocorre entre os anos de 1933-42, reforçou o surto migratório para a região central do estado. Goiânia passa desde então a dividir com o município de Anápolis, que já capitalizava um surto de desenvolvimento, as funções de eixo econômico e pólo de atração populacional. A importância de Goiânia aumenta ainda mais nos anos de 1950, quando recebe a ligação ferroviária (IPEA, 2002).

A integração regional brasileira se fortaleceu por volta dos anos de 1950, quando investimentos em infraestrutura, principalmente rodoviária, ampliaram os fluxos de comércio. No caso do Centro-Oeste, essa intensificação de comércio ocorreu com a "Marcha para o Oeste", no governo Vargas, com o intuito de promover a ocupação dos vazios demográficos por meio de absorção dos excedentes populacionais que faziam pressão no Centro-Sul do país, encaminhando-os para áreas que produziam matérias-primas e gêneros alimentícios (ARBEX JR e OLIC, 1996). No estado de Goiás, o aumento do fluxo de comércio teve como 
um dos embriões a instalação da primeira colônia agrícola, em 1941, na cidade de Ceres (KRENAC at al., 1989).

Com o Plano de Metas do governo de Juscelino Kubitschek (1956-61), inicia-se uma importante fase para o Centro-Oeste: a construção de Brasília. Conforme ressalta Diniz (2001), a construção de Brasília foi o elemento de maior impacto na integração econômica do território brasileiro. Ela passou a funcionar como o nódulo de integração decorrente da construção dos grandes troncos rodoviários: Brasília-Belém; Brasília-Belo Horizonte; Brasília-São Paulo; Brasília-Cuiabá; Brasília-Barreiras, e suas ramificações. O crescimento de Brasília, em si, a expansão agropecuária e seus efeitos sobre o crescimento urbano e de suas atividades permitiram que o Centro-Oeste se transformasse em uma das regiões mais dinâmicas do país.

No final da segunda metade da década de 1960 ocorre a entrada de novos produtos agrícolas, tais como a soja e a cana-de-açúcar. Essas culturas, por possuírem maiores oportunidades de exportação e servirem de insumo para indústria, foram gradativamente ocupando espaço das culturas tradicionais, como o arroz e o feijão. Pode-se dizer que a ocupação e a transformação produtiva da região, que já contava com amplas políticas de desenvolvimento regional, continuaram a contar com decisivos investimentos e incentivos públicos, que favoreceram, em grande medida, a implantação de uma agropecuária moderna. Com políticas gerais e específicas, o governo federal teve grande influência nesses aspectos (ARRIEL, 2010).

Com relação às políticas públicas de cunho específico à região, destacam-se: (1) Programas Integrados de Colonização (criados a partir de 1970) - com objetivo de absorver os excedentes populacionais do Centro-sul e Nordeste; (2) Programa de Incentivo Fiscal para Amazônia Legal (criado em 1966) - visando atrair investimentos para áreas compreendidas nesta localização; (3) Programa de Desenvolvimento dos Cerrados (Polocentro - criado em 1975) - considerado um dos programas mais completos, que visava a implantação da agropecuária na concepção de polos de desenvolvimento; (4) Programa de Cooperação NipoBrasileira para o Desenvolvimento dos Cerrados (Prodecer I - 1976) - promoção e expansão da agricultura moderna nos cerrados e; (5) outros, como Prodepan, Prodegran Geoeconômica, Poloamazônia e Polonoroeste (IPEA, 2002).

A implementação desse conjunto de políticas proporcionou a modernização das práticas agropecuárias e induziu a integração dessa atividade produtiva à indústria, na medida em que a indústria (a montante) fornecia insumos à agropecuária, que, por sua vez, alimentava a indústria (a jusante). Para Estevam (2004), o interesse do Estado brasileiro em modernizar a 
agricultura era no intuito de fortalecer o mercado consumidor para as indústrias de base, o que de fato ocorreu.

O Ipea (2002) sintetiza os principais fatos ocorridos no Centro-Oeste até os anos 1980: (1) a migração constituiu-se em elemento importante para a ocupação regional, desde as décadas de 50 e 60, atraída pela nova capital federal e pelos projetos de colonização; (2) a infraestrutura implantada nesse período e a expansão populacional estimularam transformações na estrutura produtiva, preparando o Centro-Oeste para a modernização agropecuária dos anos 70 e 80, desdobrada em um importante complexo agroindustrial de grãos-carnes.

No início dos anos 1980, o movimento migratório da população se dá do meio rural para os centros urbanos, devido à expansão da pecuária e o crescimento das atividades agrícolas, principalmente da soja. Nesse período, o Estado brasileiro pouco contribuiu para a continuidade do avanço da região, devido à crise fiscal financeira. Nesses tempos, entram em cena programas estaduais de incentivos fiscais como política agressiva de atração de investimentos, o que favoreceu ainda mais a implantação dos complexos agroindustriais. Conforme Paschoal (2009), a principal ação visando incentivar a economia foi o Fundo de Fomento à Industrialização do estado de Goiás (Fomentar) criado em 1984 e substituído pelo Programa de Desenvolvimento Industrial de Goiás (Produzir), em 2000.

Dessa forma, o processo migratório, o aumento da infraestrutura causada pela construção de Brasília, as políticas públicas federais e os incentivos estaduais favoreceram o estado de Goiás. Isso contribuiu para que, a partir dos anos 1990, a economia goiana apresentasse desempenho bastante positivo, alcançando resultados econômicos superiores às médias registradas para o conjunto do país. A partir daí, Goiás apresentou crescimento acima da média dos outros estados da federação e viu sua participação no produto nacional elevar de 1,8\% em 1985 para 2,7\% em 2011.

Nos anos 2000, o bom desempenho da economia goiana deveu-se principalmente aos investimentos industriais que foram responsáveis pelo adensamento das cadeias produtivas do agronegócio e diversificação da estrutura produtiva do estado. Isso contribuiu para a queda da sua dependência do setor agropecuário. Além da transformação industrial dos produtos agropecuários, "a ampliação da renda e o processo de urbanização contribuíram para a formação de um mercado interno regional com demandas por bens industriais, serviços modernos (financeiros, educacionais, saúde, informática), infraestrutura social urbana, com destaque para o saneamento, e construção civil" (MINISTÉRIO DA INTEGRAÇÃO NACIONAL, 2007). 
Esse processo de diversificação produtiva da economia goiana alterou o seu perfil em alguns aspectos. Na Tabela 1, percebe-se perda na composição da agropecuária no VA do estado (13,87\% em 1995, para 12,5\% em 2011), por outro lado, o setor industrial e do comércio registraram ganhos significativos na estrutura produtiva estadual.

Assim, o crescimento da economia goiana trouxe mudança na sua estrutura. Como os municípios fazem parte dessa estrutura estadual, busca-se caracterizá-los de acordo com o seu perfil econômico, o que também dará o perfil da economia do estado como um todo.

Tabela 1: Participação das atividades produtivas no PIB de Goiás (\%)

\begin{tabular}{|c|c|c|c|c|}
\hline Atividades & 1995 & 2000 & 2005 & 2011 \\
\hline Agropecuária & 13,9 & 14,0 & 13,4 & 12,5 \\
\hline Indústria & 20,4 & $\mathbf{2 4 , 0}$ & 26,0 & 26,8 \\
\hline Indústria extrativa & 1,1 & 1,7 & 0,8 & 1,8 \\
\hline Indústria de transformação & 11,2 & 11,5 & 13,9 & 13,8 \\
\hline Produção e distribuição de eletricidade e gás, água e esgoto e limpeza urbana & 3,1 & 4,1 & 5,3 & 4,36 \\
\hline Construção civil & 5,0 & 6,8 & 5,9 & 1,5 \\
\hline Serviços & 65,7 & 62,0 & 60,7 & 60,7 \\
\hline Comércio & 13,7 & 12,0 & 13,2 & 15,2 \\
\hline $\begin{array}{l}\text { Intermediação financeira, seguros e previdência complementar e serviços } \\
\text { relacionados }\end{array}$ & 5,2 & 3,7 & 4,5 & 5,2 \\
\hline Administração, saúde e educação públicas e seguridade social & 15,4 & 14,1 & 14,3 & 14,1 \\
\hline Outros serviços & 31,5 & 32,3 & 28,6 & 26,2 \\
\hline
\end{tabular}

\section{Referencial teórico}

Apesar de ser considerada recente - década de 50 - a Economia Regional surgiu como campo de pesquisa partindo-se da ideia de que a economia não opera num mundo sem dimensões geográficas. Além das desigualdades regionais, teve como um de seus principais focos o estudo da localização dos agentes econômicos. Duas principais correntes de pensadores ocuparam-se em estudar a localização dos meios produtivos, as teorias que dão suporte aos fatores de localização e aquelas que dão ênfase aos fatores aglomerativos.

A corrente de pensadores que desenvolveu um conjunto de teorias voltadas a fatores de localização foi denominada de Teorias Clássicas de Localização, que vai de Von Thünen, em 1826, a Isard, na década de 1950. Os autores dessa escola enfatizam, de uma forma geral, as decisões do ponto de vista da firma, que, levando em conta o papel dos custos de transporte, procuraram determinar a sua "localização ótima" (CAVALCANTE, 2002).

A partir dos anos 1950, surgem as teorias que dão ênfase aos fatores aglomerativos, tendo como inspiração as teorias keynesianas. Os principais autores foram Perroux (1967) com o conceito de "pólo de crescimento"; Myrdal (1968) com o conceito de "causação 
circular e acumulativa"; e Hirschman (1958) com os "efeitos para trás e para frente" (backward linkages e forward linkages). Esses autores deram maior ênfase a fatores dinâmicos da aglomeração, na medida em que incorporaram como fator de localização a complementaridade entre firmas e setores, assim como a noção de economia de escala mínima.

As teorias desenvolvidas por Perroux, Myrdal e Hirschman são bastante próximas, pois levam em conta que o processo de desenvolvimento só pode ser iniciado a partir de polos que se aproveitam das vantagens da aglomeração e das externalidades, para depois se propagarem por novos setores e espaços, sendo o governo o mais importante agente coordenador e incentivador do processo.

Os investimentos deveriam ser efetuados em setores selecionados, com grandes chances de sucesso, isto é, em setores com ampla possibilidade de desencadear um processo propulsor do crescimento do produto e do emprego e não como postulava a teoria do crescimento econômico equilibrado, em que um grande número de atividades produtivas, não selecionadas, receberia um bloco de investimentos simultâneos. Desta forma, acreditava-se que o avanço de setores que recebessem investimentos provocaria estímulos em outros, constituindo poderosas engrenagens do desenvolvimento (SOUZA, 1999).

Segundo Amaral Filho (2001), os modelos de desenvolvimento regional "de cima para baixo", ou seja, que parte do planejamento e da intervenção conduzidos pelo Estado nacional, recebeu diversas críticas, sendo que as principais tratam da pouca importância da questão da competitividade e por terem negligenciado a importância do progresso técnico e da inovação, essenciais para o desenvolvimento local/regional. As questões relativas às particularidades da geração e difusão das inovações em âmbito local/regional foram pouco exploradas por estes modelos de desenvolvimento regional.

Com o fim dos anos dourados e com os questionamentos da eficácia das políticas keynesianas, surge nos anos 1970, a Teoria Novo-Clássica. Isso acaba por influenciar o pensamento em economia regional. Nas palavras de Diniz e Crocco (2006), ocorreu influência tanto na teoria quanto na política de desenvolvimento regional sendo que, em termos teóricos, as duas principais alterações foram a incorporação de aspectos institucionais (formais e informais) e a valorização da capacitação local para o combate às desigualdades regionais; já em termos políticos o elemento competitividade torna-se o elemento central.

Para ser competitivo, o conhecimento e a inovação se tornam elementos essenciais (DINIZ, SANTOS E CROCCO (2006). O processo de inovação faz qualquer perspectiva de crescimento regional e de redução de desigualdades inter-regionais ficarem dependentes das 
características dos diversos "locais" e, ainda, com que as políticas de Arranjos Produtivos Locais (APL), Parques Tecnológicos e outros arranjos locais, necessitem ser pensados de acordo com as condicionantes estruturais de cada região (DINIZ E CROCCO, 2006).

Assim, o potencial produtivo de uma região pode estar atrelado ao seu posicionamento geográfico em relação a portos, rodovias, ferrovias e mercados, à existência de infraestrutura educacional, bem como às características e experiência produtiva prévia. Os "locais" devem buscar suporte necessário para criar condições para ser competitivo ou adequar, implementar e difundir conhecimento nas atividades econômicas existentes com o intuito de tornar essas atividades econômicas portadoras ou receptoras de progresso técnico.

Conforme Tavares e Porto Junior (2008), talvez pelas falhas das linhas de pesquisa anteriores em explicar o porquê de algumas regiões possuírem mais atividade econômica que outras, bem como o fato das firmas mais promissoras estarem instaladas em regiões mais densamente povoadas, surge uma nova área ou uma nova extensão da Economia Regional no início dos anos 90 denominada de Nova Geografia Econômica (NGE), que se preocupa em determinar como se dá o processo de distribuição da atividade econômica no espaço, responsável, em grande parte, pelas desigualdades regionais. De acordo com Ruiz (2003), a NGE possui base teórica no modelo centro-periferia.

Essa nova vertente tem Krugman (1991) como seu maior expoente e busca entender por que a atividade econômica se concentra em determinadas localizações e não de maneira uniforme. Apesar de ser alvo de muitas críticas ${ }^{1}$, como falhas em incorporar as diversidades sociais, a teoria da localização e a NGE se tornaram centro das atenções na teoria econômica.

Portanto, como as características locais influenciam diretamente no seu potencial e dão indicativos para que sejam tomadas decisões ou formuladas políticas com vistas a incentivar o crescimento e/ou o desenvolvimento de um local ou região, esse trabalho procura contribuir nessa direção para o caso dos municípios do estado de Goiás.

\section{Sobre os dados estatísticos e a metodologia}

Segundo De Luca (1988), o valor adicionado (VA) é uma variável da macroeconomia utilizada para aferição do Produto Interno Bruto (PIB). Conforme Rossetti (2002), este "é a soma dos bens e serviços finais produzidos pelo sistema econômico em determinado período". Isso porque se deve evitar a dupla contagem, porquanto o mesmo produto passa por diversas etapas do processo produtivo. De forma similar, pelo conceito definido pelo IBGE

\footnotetext{
${ }^{1}$ Para maiores detalhes ver Ruiz (2003).
} 
(2008), nas Contas Regionais, o VA é o valor que a atividade acrescenta aos bens e serviços consumidos no seu processo produtivo. É a contribuição ao PIB pelas diversas atividades econômicas, obtida pela diferença entre o valor de produção e o consumo intermediário absorvido por essas atividades.

Para o cálculo do PIB dos municípios, são estimados os valores adicionados para três setores de atividades: agropecuária, indústria e serviços. O PIB municipal é obtido por uma partição do PIB estadual. Este indicador não é construído com dados de produção e consumo intermediário, mas pela partição do PIB estadual. Ao total do valor adicionado das três atividades, são somados os impostos líquidos de subsídios sobre produtos, obtendo-se, então, o PIB municipal a preços de mercado.

A fim de alcançar os objetivos propostos, inicialmente foram gerados indicadores sintéticos que representam o perfil dos municípios a partir dos dados do PIB Municipal de 2011 e, em seguida, classificou-se cada um dos 246 municípios segundo o seu perfil em grupos homogêneos.

Para isso foram usadas técnicas estatísticas multivariadas de análise fatorial para gerar os indicadores sintéticos, bem como de agrupamentos com vistas à classificação dos municípios em grupos com características semelhantes, segundo a produção de riqueza do município.

\subsection{A análise fatorial}

A necessidade de se entender o relacionamento entre um grande número de variáveis fez com que os estatísticos desenvolvessem técnicas capazes de representar de modo sintético grande conjunto de dados numéricos (técnicas de análise multivariada). Muito utilizadas são as "Análises de Componentes Principais e Análise de Fatores". São técnicas que trabalham juntas. Conforme Hair Jr et al. (2009) a análise fatorial é uma técnica estatística multivariada de interdependência cujo propósito principal é definir a estrutura inerente entre as variáveis na análise. Deste modo, um grande número de variáveis correlacionadas podem ser reduzidas em um número menor de variáveis não correlacionadas (fatores) que sintetizam as principais informações das variáveis originais.

$\mathrm{Na}$ extração dos fatores deve-se considerar a melhor combinação linear entre as variáveis. Existem alguns métodos para extrair essa combinação. Nesse trabalho levou-se em consideração o método das componentes principais com o critério de rotação varimax. Dessa maneira, extraiu-se um número reduzido de fatores e os escores fatoriais finais de cada elemento da amostra - para o trabalho aqui desenvolvido, municípios. O critério de Kaiser foi 
utilizado para determinar o número de fatores. Esse critério considera os autovalores maiores que a unidade.

\subsection{A análise de clusters ou agrupamento}

A análise de clusters ou grupamento é uma técnica de estatística multivariada com a finalidade principal de agrupar objetos com base em características semelhantes em um conjunto de variáveis. Ou, em outras palavras, definir a estrutura dos dados colocando as observações mais parecidas em grupos (HAIR JR. et al., 2009).

Nessa técnica, quando itens (unidades ou casos) são agrupados, a proximidade é usualmente indicada por alguma espécie de distância. A utilizada nesse trabalho é o quadrado da distância Euclidiana, comumente usada na busca de um critério de similaridade. Para os procedimentos de agrupamento foi utilizado o método das $K$-médias. Conforme Bussab et al., (1990), esse método de partição fornece indicações mais precisas para agrupar objetos com pequenas variações e é um critério que privilegia a homogeneidade dentro do grupo e heterogeneidade entre os grupos. Ele leva em consideração a soma dos quadrados residuais baseado na Análise de Variância. Assim, quanto menor for este valor, mais homogêneos são os elementos dentro de cada grupo e melhor será a partição.

\subsection{As variáveis consideradas}

As variáveis utilizadas neste estudo se referem aos municípios goianos e são obtidas a partir do Produto Interno Bruto (PIB) Municipal - 2011, divulgado pela Secretaria de Gestão e Planejamento do Estado de Goiás - via Instituto Mauro Borges e em parceria com o IBGE, e tem como objetivo verificar o perfil da produção do município segundo o setor de atividade e o peso dessa produção no total do município e no estado de Goiás. As variáveis consideradas no estudo são apresentadas no Quadro 1. 
Quadro 1: Variáveis consideradas para caracterizar o perfil da produção do município segundo o setor de atividade

\begin{tabular}{|c|}
\hline \% do VA da agropecuária do município no total do VA do município. \\
\hline \% do VA da indústria do município no total do VA do município. \\
\hline \% do VA dos serviços de administração pública do município no total do VA do município. \\
\hline \% do VA da agropecuária do município no total do VA da agropecuária estadual. \\
\hline \% do VA da indústria do município no total do VA da indústria estadual. \\
\hline $\begin{array}{l}\text { \% do VA dos serviços do município, exceto de administração pública, no total do VA dos serviços sem } \\
\text { administração pública estadual. }\end{array}$ \\
\hline $\begin{array}{l}\text { \% do VA dos serviços de administração pública do município no total do VA dos serviços de administração } \\
\text { pública estadual. }\end{array}$ \\
\hline onte: Segplan/IMB-GO. \\
\hline
\end{tabular}

\section{Resultados e discussões}

Com a finalidade de reduzir a dimensionalidade das variáveis, aplicou-se a análise fatorial por meio do método dos componentes principais, obtendo-se desse modo indicadores sintéticos (escores fatoriais). O município de Goiânia foi excluído da análise, pois seu perfil é diferenciado em relação aos outros 245 municípios do estado.

Desse modo, obtiveram-se três fatores que explicam $86,42 \%$ da variabilidade total dos dados. A escolha do número de fatores deu-se a partir do número de autovalores da matriz de correlação maiores do que a unidade, já que um autovalor pequeno contribui pouco na explicação das variações das variáveis originais ${ }^{2}$ (Tabela 2 ).

Tabela 2: Resultados da análise fatorial

\begin{tabular}{cccc}
\hline Fator & Autovalor & \% de Variância explicada & \% de Variância Acumulada \\
\hline 1 & 3,30 & 47,15 & 47,15 \\
2 & 1,62 & 23,07 & 70,22 \\
3 & 1,13 & 16,20 & 86,42 \\
\hline
\end{tabular}

Fonte: Resultados obtidos com os dados da Segplan/IMB-GO.

Notas: 1) Os dados estão ortogonalizados com a rotação varimax.

2) Exclusive Goiânia

Os resultados da análise fatorial podem ser interpretados por meio das "cargas fatoriais", que são medidas de correlação entre o fator extraído da análise e as variáveis originais, como consta na Tabela 3.

\footnotetext{
${ }^{2}$ Os resultados foram obtidos com o Software Statgraphics XV.I.
} 
Tabela 3: Carga fatorial das variáveis

\begin{tabular}{|c|c|c|c|}
\hline Variável & Fator 1 & Fator 2 & Fator 3 \\
\hline $\begin{array}{l}\text { \% do VA dos serviços de administração pública do município no total do } \\
\text { VA dos serviços de administração pública estadual. }\end{array}$ & 0,94 & 0,06 & 0,13 \\
\hline $\begin{array}{l}\% \text { do VA dos serviços do município, exceto de administração pública, } \\
\text { no total do VA dos serviços sem administração pública estadual. }\end{array}$ & 0,95 & 0,14 & 0,09 \\
\hline$\%$ do VA da indústria do município no total do VA da indústria estadual. & $\mathbf{0 , 8 3}$ & 0,23 & 0,28 \\
\hline $\begin{array}{l}\text { \% do VA da agropecuária do município no total do VA da agropecuária } \\
\text { estadual. }\end{array}$ & 0,33 & 0,71 & $-0,15$ \\
\hline $\begin{array}{l}\% \text { do VA dos serviços de administração do município no total do VA do } \\
\text { município. }\end{array}$ & $-0,05$ & $-0,92$ & $-0,16$ \\
\hline \% do VA da agropecuária do município no total do VA do município. & $-0,34$ & 0,41 & $-0,77$ \\
\hline$\%$ do VA da indústria do município no total do VA do município. & 0,11 & 0,25 & $\mathbf{0 , 9 4}$ \\
\hline
\end{tabular}

Fonte: Resultados obtidos com dados da SEGPLAN/IMB-GO.

Obs.: Exclusive Goiânia

A partir dos resultados apresentados na Tabela 3, os fatores podem ser interpretados da seguinte maneira:

Fator 1 - esse fator reflete maior peso dos serviços (com e sem a administração pública) e da indústria do município nos respectivos VA's do Estado. Valores altos nesse indicador significam que os serviços e a indústria têm importância tanto no âmbito do município como no do Estado.

Fator 2 - produção representativa de serviços de administração pública (APU) no município ou produção representativa da agropecuária tanto no município quanto no Estado. Ou seja, há uma forte dependência do município pela agropecuária ou pelos serviços de administração pública. Altos valores e positivos nesse fator significam produção representativa da agropecuária e valores baixos e negativos apontam para uma maior representação da administração pública no município. Ressalta-se a correlação negativa entre essas variáveis.

Fator 3 - produção representativa da indústria ou da agropecuária no município. Altos valores e positivos nesse fator significam produção representativa da indústria no município e valores baixos e negativos indicam representatividade da agropecuária, também no município.

Ainda, as comunalidades (Tabela 4) mostram a quantia da variância de uma variável que é explicada pelos três fatores conjuntamente. Segundo Hair Jr et al. (2009), valores altos nessa medida é um indicativo de que uma grande parte da variância de uma variável foi extraída pela solução fatorial. Desta maneira, verifica-se que todas as variáveis compartilham mais de $65 \%$ de sua variância com os três fatores, apontando um bom ajuste do modelo fatorial. 
Tabela 4: Comunalidadades

\begin{tabular}{lc}
\hline \multicolumn{1}{c}{ Variáveis } & Comunalidadades \\
\hline \% do VA dos serviços de administração pública do município no total do VA do estado. & 0,91 \\
\% do VA dos serviços do município, exceto de administração pública, no total do VA do & 0,94 \\
estado. & 0,83 \\
\% do VA da indústria do município no total do VA da indústria do estado. & 0,65 \\
\% do VA da agropecuária do município no total do VA da agropecuária do estado. & 0,88 \\
\% do VA da agropecuária do município no total do VA do município. & 0,88 \\
\% do VA dos serviços de administração pública no total do VA do município. & 0,97 \\
\hline do VA da indústria do município no total do VA do município. &
\end{tabular}

Fonte: Resultados obtidos com os dados da Segplan/IMB-GO.

A partir desses resultados, é possível obter três escores fatoriais que expressam as dimensões apresentadas na Tabela 3. Esses escores nada mais são do que combinações lineares das variáveis originais. Da mesma forma que as "cargas fatoriais", esses coeficientes de cada variável expressam seu "peso" na composição do indicador. Dessa forma, para cada um dos 245 municípios da análise (exclusive Goiânia), é possível sintetizar em apenas três indicadores a maior parte das informações contidas nas variáveis originais $(86,42 \%)$. Os coeficientes desses indicadores para as variáveis originais estão apresentados na Tabela 5. Essas informações serão úteis para as análises mais adiante.

Tabela 5: Coeficientes dos escores fatoriais

\begin{tabular}{|c|c|c|c|}
\hline Variáveis & Fator 1 & Fator 2 & Fator 3 \\
\hline $\begin{array}{l}\text { \% do VA dos serviços de administração pública do município no total do VA } \\
\text { dos serviços de administração pública estadual. }\end{array}$ & 0,39 & $-0,09$ & $-0,10$ \\
\hline $\begin{array}{l}\text { \% do VA dos serviços do município, exceto de administração pública, no total } \\
\text { dos serviços sem administração pública do VA estadual. }\end{array}$ & 0,39 & $-0,04$ & $-0,13$ \\
\hline \% do VA da indústria do município no total do VA da indústria do estado. & 0,29 & 0,04 & 0,03 \\
\hline $\begin{array}{l}\% \text { do VA da agropecuária do município no total do VA da agropecuária do } \\
\text { estado. }\end{array}$ & 0,08 & 0,40 & $-0,14$ \\
\hline \% do VA da agropecuária do município no total do VA do município. & $-0,05$ & 0,27 & $-0,45$ \\
\hline \% do VA dos serviços de administração pública no total do VA do município. & 0,14 & $-0,60$ & $-0,15$ \\
\hline \% do VA da indústria do município no total do VA do município. & $-0,18$ & 0,19 & $-0,13$ \\
\hline
\end{tabular}

Fonte: Resultados obtidos com dados da Segplan/IMB-GO.

Obs.: Exclusive Goiânia

\subsection{Análise dos agrupamentos}

Com a finalidade de identificar grupos homogêneos de municípios segundo os três fatores gerados pela análise fatorial, utilizou-se a técnica de análise de agrupamentos com o objetivo de identificar padrões de similaridades existentes entre os elementos do conjunto de informações. Os municípios foram agrupados adotando-se como critério de proximidade o 
quadrado da distância Euclidiana e para procedimentos de agrupamento o método das $K$ médias.

Para utilizar o método da $K$ - médias, técnica de conglomerado não hierárquica, é necessário o número de grupos pré-estabelecidos. Segundo Mingoti (2007), as técnicas hierárquicas são úteis em análises exploratórias dos dados, com intuito de identificar o valor provável do número de grupos. Desta maneira, para se determinar o número de agrupamentos que melhor traduz as similaridades entre os municípios em estudo, inicialmente foi utilizado o método de Ward, que se baseia em ligar os objetos formando grupos que minimizam a variância dentro dos grupos. Juntando-se a isso, para fazer o corte de quantos grupos minimizam essa variância utilizou-se o critério de ganho de inércia ${ }^{3}$. Tais métodos sugeriram a partição formada por quatro agrupamentos. Além disso, foram criadas partições de três a cinco grupos observando-se os ganhos percentuais na variabilidade dos grupos. Após a análise dessas técnicas optou-se pela partição formada por quatro agrupamentos. Com tais critérios, os agrupamentos finais e as médias dos fatores para cada grupo são os que seguem (Tabela 6).

Tabela 6: Valores médios dos escores fatoriais, por agrupamentos

\begin{tabular}{|c|c|c|c|c|c|}
\hline \multirow{2}{*}{ Fator } & \multicolumn{4}{|c|}{ Agrupamentos } & \multirow{2}{*}{ Total } \\
\hline & Grupo 1 & Grupo 2 & Grupo 3 & Grupo 4 & \\
\hline Fator 1 & $-0,02$ & $-0,02$ & 4,45 & $-0,24$ & \\
\hline Fator 2 & $-0,94$ & 0,53 & 1,11 & 0,50 & \\
\hline Fator 3 & 0,02 & 1,55 & 0,27 & $-0,70$ & \\
\hline Total de municípios & 89 & 44 & 8 & 104 & 245 \\
\hline
\end{tabular}

Fonte: Resultados obtidos com dados da Segplan/IMB-GO.

Obs.: Exclusive Goiânia

Os grupos formados podem ser nominados conforme o perfil dos municípios que os compõem ${ }^{4}$. O Grupo 1, o qual denominamos de "Administração Pública", contém municípios com forte dependência dos recursos do poder público municipal; o Grupo 2 contém os municípios que apresentam "Indústria com relevância no município" como característica predominante - normalmente associada a atividade de extração mineral, energia elétrica, sucroenergética ou de frigoríficos. Estas duas últimas comprovam por que esse grupo também teve no Fator 2 um escore que demonstra alguma significância do setor agropecuário no município, ou seja, há uma integração agropecuária e indústria. O Grupo 3 possui atividades

\footnotetext{
${ }^{3}$ Determina-se ganho de inércia a partir das variabilidades encontradas pelo método de agrupamento de Ward. A partir dessas variabilidades e, durante a formação dos grupos, verifica-se em qual momento ocorre a maior perda relativa dessa variabilidade na transição de um agrupamento para outro. Nesse momento, determina-se o número de agrupamentos. Para maiores detalhes veja em HUSSON, LÊ e PAGÈS (2011).

${ }^{4}$ Para ver a característica de cada um dos municípios goianos veja o Apêndice deste trabalho.
} 
de "Serviços e indústria com relevância no estado"; o Grupo 4 tem predominância da agropecuária tanto no município como no estado, assim denominado de "Agropecuária". O Quadro 2 resume essas informações bem como a Figura 1 espacializa-as com informações adicionais.

Quadro 2: Número de grupos, descrição e perfil

\begin{tabular}{|l|l|}
\hline \multicolumn{1}{|c|}{ Grupo/Descrição } & \multicolumn{1}{|c|}{ Perfil } \\
\hline $\begin{array}{l}\text { Grupo 1: Municípios com forte dependência dos recursos da administração } \\
\text { pública }\end{array}$ & Administração Pública \\
\hline $\begin{array}{l}\text { Grupo 2: Municípios onde a indústria tem relevância no município } \\
\begin{array}{l}\text { Grupo 3: Municípios com indústria e serviços de relevância na economia } \\
\text { estadual }\end{array}\end{array}$ & $\begin{array}{l}\text { Indústria com relevância no } \\
\text { município } \\
\text { relevância no estado }\end{array}$ \\
\hline $\begin{array}{l}\text { Grupo 4: Municípios com sua economia caracterizada pela produção } \\
\text { agropecuária }\end{array}$ & Agropecuária \\
\hline
\end{tabular}

Fonte: Elaborado pelos autores. 
Figura 1: Grupos formados, seu perfil e participação (\%) na população e PIB do Estado de Goiás, bem como distribuição do beneficiamento de minérios e usinas sucroenergéticas.

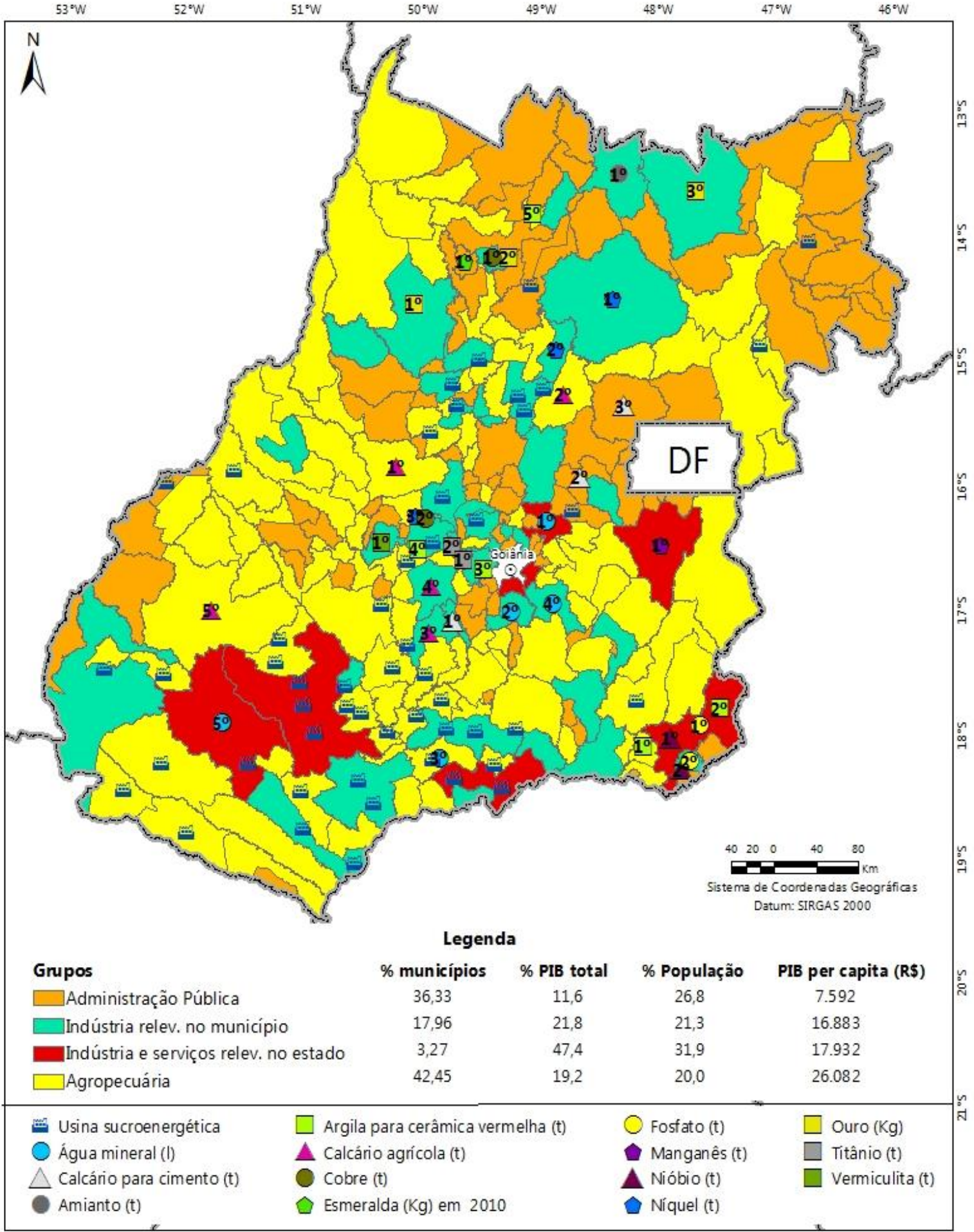

Elaboração dos autores

Nota: Para não poluir a figura acima tirou-se o nome dos municípios, o que pode ser visualizado em Anexo.

O número absoluto e relativo de municípios nesses grupos e os aspectos gerais relacionados com o PIB e a população também são colocados na Tabela 7 e no Gráfico 1, a seguir. 
Tabela 7: Número de municípios, população, PIB total e per capita, segundo agrupamentos

\begin{tabular}{|c|c|c|c|c|c|c|c|}
\hline \multirow{2}{*}{ Grupos } & \multicolumn{2}{|c|}{ Municípios } & \multicolumn{2}{|l|}{ PIB total } & \multicolumn{2}{|c|}{$\begin{array}{l}\text { População (em } \\
\text { mil hab.) }\end{array}$} & \multirow{2}{*}{$\begin{array}{c}\text { PIB per } \\
\text { capita }(\mathbf{R} \$)\end{array}$} \\
\hline & Qtd. & $\%$ & Em milhões de R\$ & $\%$ & Hab. & $\%$ & \\
\hline $\begin{array}{l}\text { Indústria e serviços com } \\
\text { relevância no estado }\end{array}$ & 8 & 3,27 & 39.619 & 47,4 & 1.519 & 31,9 & 26.082 \\
\hline $\begin{array}{l}\text { Indústria com relevância no } \\
\text { município }\end{array}$ & 44 & 17,96 & 18.183 & 21,8 & 1.014 & 21,3 & 17.932 \\
\hline Agropecuária & 104 & 42,45 & 16.073 & 19,2 & 952 & 20,0 & 16.883 \\
\hline Administração Pública & 89 & 36,33 & 9.725 & 11,6 & 1.281 & 26,8 & 7.592 \\
\hline
\end{tabular}

Fonte: SEGPLAN/IMB-GO.

Elaborado pelos autores. Obs.: Exclusive Goiânia.

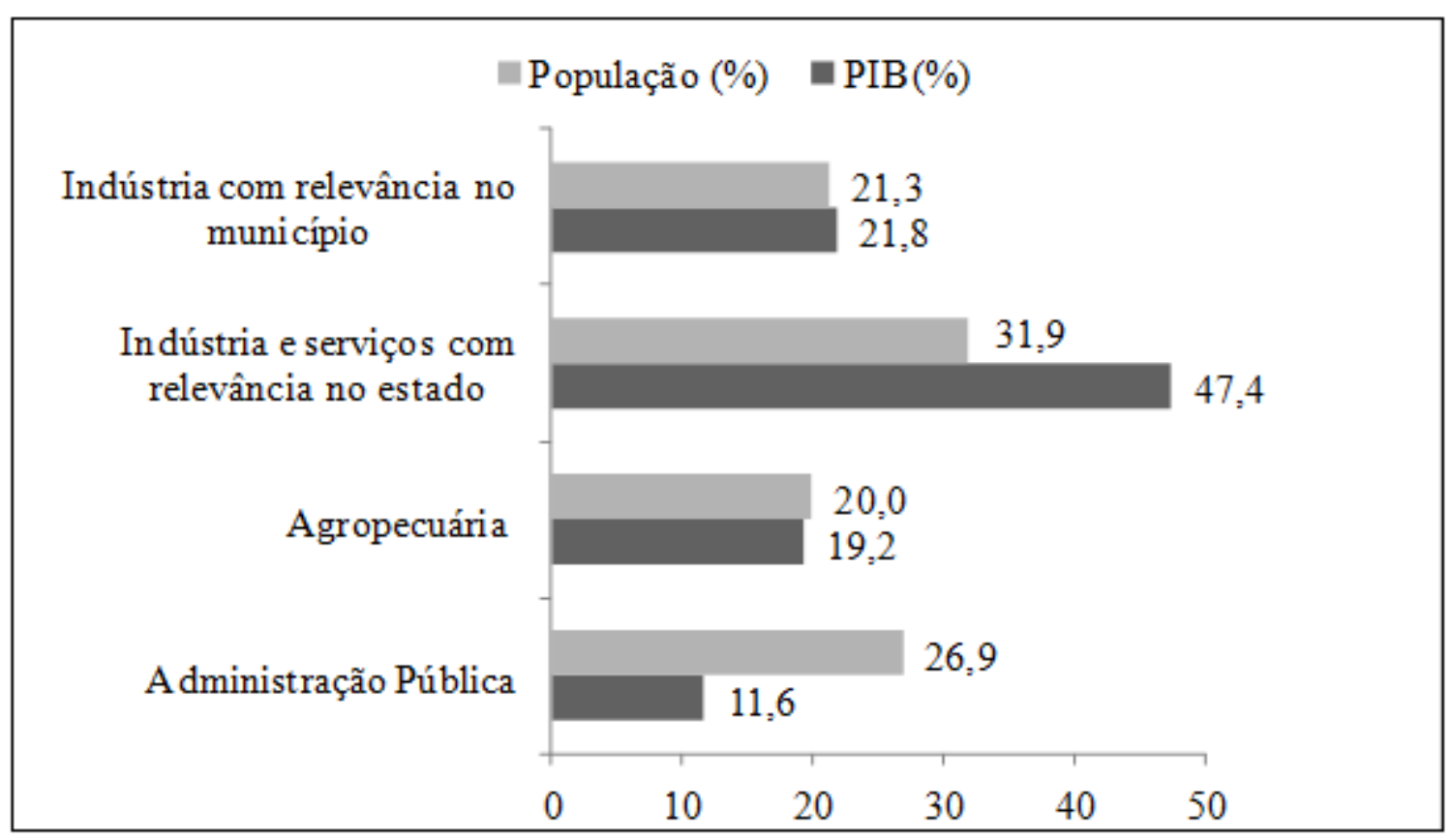

Gráfico 1: Participação do PIB e da população, segundo agrupamentos.

Elaborado pelos autores.

Percebe-se que a maior parte dos municípios goianos tem a sua economia ligada à agropecuária $(42,45 \%)$ ou dependem dos recursos da administração pública $(36,33 \%)$, ou seja, um total de $(78,5 \%)$, sendo que esses municípios representam apenas 30,8\% do total do PIB e 46,8\% da população estadual (Gráfico 1).

Além disso, têm um PIB Per capita de $\mathrm{R} \$ 11.553$, bem abaixo da média do estado ( $\mathrm{R} \$$ 18.298,59). Normalmente são municípios menores em população e que dependem de transferências de recursos de outros entes da federação para execução e oferta de serviços públicos, principalmente do Fundo de Participação dos Municípios - FPM, ou seja, eles não têm arrecadação própria significante. 
O grupo que possui peso considerável tanto na composição do PIB, 47,4\%, quanto da população, 31,9\%, é o de Indústria e Serviços (com e sem a administração pública) relevantes no estado, porém é o grupo que apresenta o menor número de municípios, apenas 8 (exclusive Goiânia e em vermelho na Figura 1). Nesse grupo, essas duas atividades além de terem grande participação no VA total dos municípios, têm também relevância no VA total dessas atividades no Estado. Nota-se, também que o PIB Per capita de R\$ 26.082 está muito acima do estadual. Além disso, esses municípios localizam-se na metade sul do Estado refletindo, ainda, a grave disparidade histórica entre a metade norte e sul.

O Grupo 2, municípios onde a indústria tem relevância no município (em verde na Figura 1), apresenta essa característica por possuir usina sucroenergética, empresa de beneficiamento de minérios, algum frigorífico ou usina hidrelétrica. Ou seja, uma empresa de qualquer desses segmentos mudou o perfil agropecuário ou de administração pública desses municípios.

No Gráfico 1, nota-se algumas peculiaridades dos grupos quanto à participação no Produto Interno Bruto (PIB) e na população estadual. Os Grupos 2 (Indústria tem relevância no município) e 4 (Agropecuária) apresentam equilíbrio na distribuição da riqueza gerada e da sua população. Por outro lado, os Grupos 1 (Administração Pública) e 3 (indústria e serviços de relevância na economia estadual) possuem grande disparidade entre a sua participação na riqueza e população. O Grupo 1 tem participação populacional no estado (26,8\%) de mais do que o dobro da riqueza gerada $(11,6 \%)$. Já o Grupo 3 tem 1,49 vezes mais riqueza gerada $(47,4 \%)$ do que sua população $(31,9 \%)$.

Quanto ao peso dos VA's nos grupos formados, apresenta-se a Tabela 8 que mostra as médias dos pesos das variáveis originais conforme os agrupamentos gerados. 
Tabela 8: Participação percentual dos VA’s por agrupamentos

\begin{tabular}{|c|c|c|c|c|c|}
\hline Participação dos VA's & $\begin{array}{c}\text { Administração } \\
\text { Pública }\end{array}$ & Agropecuária & $\begin{array}{c}\text { Indústria } \\
\text { (Estado) }\end{array}$ & $\begin{array}{c}\text { Indústria } \\
\text { (município) }\end{array}$ & $\begin{array}{l}\text { Média } \\
\text { Geral }\end{array}$ \\
\hline $\begin{array}{l}\text { \% do VA da agropecuária do } \\
\text { munic. no total do VA do } \\
\text { município }\end{array}$ & 25,26 & 44,92 & 11,51 & 19,93 & 32,20 \\
\hline $\begin{array}{l}\% \text { do VA dos serviços de } \\
\text { APU do munic. no total do } \\
\text { VA do munic. }\end{array}$ & 28,40 & 15,50 & 10,22 & 15,50 & 20,89 \\
\hline $\begin{array}{l}\% \text { do VA da indústria do } \\
\text { munic. no total do VA do } \\
\text { munic. }\end{array}$ & 11,91 & 10,09 & 28,24 & 31,75 & 15,23 \\
\hline $\begin{array}{l}\% \text { do VA da agropecuária do } \\
\text { munic. no total do VA da } \\
\text { agropecuária do estado }\end{array}$ & 0,11 & 0,50 & 2,42 & 0,42 & 0,41 \\
\hline $\begin{array}{l}\% \text { do VA da indústria do } \\
\text { munic. no total do VA da } \\
\text { indústria do estado }\end{array}$ & 0,06 & 0,09 & 4,00 & 0,74 & 0,32 \\
\hline $\begin{array}{l}\% \text { do VA dos serviços do } \\
\text { munic. exceto de APU, no } \\
\text { total do VA do estado }\end{array}$ & 0,10 & 0,11 & 3,64 & 0,26 & 0,25 \\
\hline $\begin{array}{l}\% \text { do VA dos serviços de } \\
\text { APU do munic. no total do } \\
\text { VA do estado }\end{array}$ & 0,22 & 0,17 & 2,69 & 0,37 & 0,31 \\
\hline
\end{tabular}

As informações da Tabela 8 corroboram informações já mencionadas quanto aos agrupamentos $^{5}$ e as conclusões podem ser colocadas da seguinte maneira:

- Os municípios do Grupo 1 (Administração pública) têm sua maior dependência econômica da administração pública. Nota-se isso na Tabela 9 pelo maior percentual $(28,4 \%)$ de participação nessa atividade. Normalmente, esses municípios estão associados à maior dependência de transferências de recursos governamentais (FPM e FPE, principalmente). Além disso, possuem os menores escores no Fator 1 e 3 (Tabela 3 e Tabela 5), reforçando o peso da administração pública na composição do grupo. Possuem também a segunda maior participação populacional.

- O Grupo 2 tem a atividade industrial com relevância no município que o compõe. Isso se verifica por apresentar a maior participação percentual do VA industrial nos municípios (31,75\%, Tabela 10), bem como maior escore médio fatorial no Fator 3 (Tabela 6), que indica maior peso dessa atividade na economia desse grupo de municípios. O caráter industrial destes municípios é representado, principalmente, pela agroindustrialização.

\footnotetext{
${ }^{5}$ Os municípios e o grupo a que pertence encontra-se em Apêndice.
} 
- O Grupo 3 possui serviços (com e sem a administração pública) e indústria relevantes no Estado. As duas atividades são significativas na economia desses municípios. Esses municípios estão entre os que possuem maior força econômica no Estado e, por isso, suas economias são mais dinâmicas. Esse grupo apresenta a maior percentagem média da atividade de indústria no VA industrial do Estado e a segunda no VA industrial nos municípios. Ainda, tem o maiores escores médios no Fator 1 e Fator 2 (Tabela 6), o que indica a grande importância dos serviços e da indústria no município e no Estado.

- O Grupo 4 tem seu perfil baseado na agropecuária. Isso é percebido observando-se os percentuais médios dos VA's da Tabela 8, que indicam os maiores pesos nessas atividades. Também, esse grupo tem o menor escore no Fator 3 (Tabela 6), sendo que valores pequenos nesse fator indicam maior participação da agropecuária no VA do município. Além disso, esse grupo apresenta os segundo maior escore no Fator 2, apontando, também, participação da agropecuária no VA do Estado. Esse raciocínio também é válido ao analisar os coeficientes fatoriais do Fator 2 da Tabela 3.

\section{Considerações finais}

O trabalho teve por objetivo caracterizar os municípios do estado de Goiás conforme suas atividades econômicas, tomando-se por base o Valor Adicionado (VA) por atividade, de cada município, e seus respectivos pesos nos VAs específicos no município bem como no Estado.

Com isso, percebe-se que a maior parte dos municípios goianos $(78,5 \%)$ tem o perfil da sua economia ligado à agropecuária e serviços de administração pública, porém esses municípios representam apenas $30,8 \%$ do total do PIB e 46,9\% da população total, bem como têm o menor PIB per capita, R\$ R \$ 11.553, abaixo da média do Estado, que é de R\$ R\$ 18.298,59. Normalmente são municípios pequenos e que dependem de transferências de recursos de outros entes da federação para execução e oferta de serviços públicos, principalmente do Fundo de Participação dos Municípios - FPM, ou seja, eles não têm um fluxo de produção/renda com capacidade de gerar arrecadação própria para sustentar sua economia.

No Estado, apenas 8 municípios (exclusive Goiânia) dos 245 têm características de economias mais desenvolvidas, sendo que eles possuem o maior peso na composição do PIB, $47,4 \%$, mas são o segundo quanto à população, 31,9\%. Percebe-se que a participação da renda 
nesses municípios é maior do que a da população, comprovado pelo PIB per capita de R\$ 26.082, muito acima do estadual.

Há um grupo caracterizado como indústria relevante no município. Esses municípios normalmente têm seus VA's industriais ligados à atividade de energia (usinas hidrelétricas), sucroenergética (usinas de etanol), extração mineral ou frigoríficos. Esse conjunto de municípios responde por $21,8 \%$ do PIB estadual, tendo a maior participação no VA industrial do município, com 31,75\%. Tem, ainda, o segundo maior PIB per capita entre os grupos, R\$ 17.932 .

Assim, apesar da economia goiana crescer acima da média do conjunto das unidades da federação, a concentração de renda é algo notável, considerando as características de produção baseado nos VA's dos seus municípios e grupos com características semelhantes.

\section{Referências}

AMARAL FILHO, J. A endogeneização no desenvolvimento econômico regional e local. Revista Planejamento e Políticas Públicas, IPEA, Brasília, n. 23, p.261-286, jun., 2001.

ARBEX JR. J.; OLIC, N. B. Rumo ao Centro-Oeste: o Brasil em regiões. Editora Moderna, São Paulo, 1996.

ARRIEL, M. F. Perfil produtivo e dinâmica espacial da indústria goiana - 1999-2007. Dissertação (mestrado) - Pontifícia Universidade Católica de Goiás, Departamento de Ciências Econômicas, 2010. Disponível em:

$<$ http://tede.biblioteca.ucg.br/tde busca/arquivo.php?codArquivo=762 > . Acesso em: 05 de dez. 2010.

BUSSAB, W.O.; MIAZAK, E.S.; ANDRADE, D.F. Introdução à Análise de Agrupamentos. $9^{\circ}$ Simpósio Brasileiro de Probabilidade e Estatística. São Paulo: IME USP, 1990. Disponível em: <http://www.scribd.com/doc/4567031/Livro-de-Analise-deAgrupamento. Acesso em 20/11/2010>. Acesso em: 05 de nov. 2010.

CAVALCANTE, L. R. M. T. Produção teórica em economia regional: uma proposta de sistematização. Desenbahia, 2002. Disponível em:

<http://www.desenbahia.ba.gov.br/estudos/artigos.asp >. Acesso em: 05 de nov. 2010.

DE LUCA. Demonstração do valor adicionado: do cálculo da riqueza criada pela empresa ao valor do PIB. São Paulo: Atlas, 1998.

DINIZ C. C. A questão regional e as políticas governamentais no Brasil. Texto para discussão ${ }^{0}$ 159. Belo Horizonte: CEDEPLAR, Universidade Federal de Minas Gerais, 2001.

DINIZ, C. C.; CROCCO, M. Economia regional e urbana contribuições teóricas recentes. Editora UFMG. Belo Horizonte, 2006. 
DINIZ, C. C.; SANTOS, F.; CROCCO, M. Conhecimento, inovação e desenvolvimento regional/local: IN Economia regional e urbana contribuições teóricas recentes. Editora UFMG. Belo Horizonte, 2006.

ESTEVAM, L. A. O tempo da transformação: estrutura e dinâmica da formação econômica de Goiás. Goiânia: Ed. da UCG, 2004.

HAIR JR, E.J.; BLACK, C. B.; BABIN, B.J.; TATHAN, L. R. Análise multivariada de dados, $6^{\text {a }}$ Ed. Bookman, 2009.

HIRSCHMAN, A. O. Desenvolvimento por efeitos em cadeia: uma abordagem generalizada. IN: SORJ, B.; CARDOSO, F. H.; FONT, M. (Orgs.). Economia e movimentos sociais na américa latina. São Paulo: Brasiliense, 1985.

HUSSON, F.; LÊ, S.; PAGÈS, J. Exploratory Multivariate Analysis by Example Using R. New York: Chapman \& Hall/CRC, 2011.

IBGE. Instituto Brasileiro de Geografia e Estatística. Série Relatórios Metodológicos Contas Regionais do Brasil. Rio de Janeiro 2008.

IPEA/IBGE/NESUR (IE-UNICAMP). Caracterização e tendências da rede urbana do Brasil: redes urbanas regionais. Brasília: IPEA, 2002.

KRENAK, A.; MOREIRA, R.; SADER, R.; FAULHABER, P.; TARELHO, L. C.; OLIVEIRA, L. C.; CASTRO, B.; BARBOSA, Y. M. Território e cidadania: Da luta pela terra ao direito à vida. Editora Marco Zero, Pinheiros -SP, 1989.

KRUGMAN, P. Geographi and trade. Massachusetts: The MIT, 1991. Disponível em: $<$ http://books.google.com.br/books?hl=pt-

$\underline{\text { BR\&lr}=\& \mathrm{id}=\mathrm{AQDodCHOgJYC \& oi}=\mathrm{fnd} \& \mathrm{pg}=\mathrm{PP} 7 \& \mathrm{dq}=\mathrm{KRUGMAN},+ \text { Paul.+Geography }+ \text { and }}$ + trade\&ots=Pxm21kMLik\&sig=y6WX-

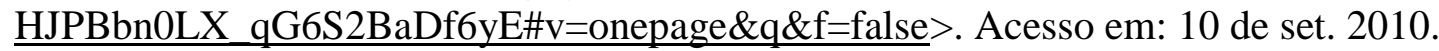

MINGOTI, S. A. Análise de dados através de métodos de estatística multivariada: uma abordagem aplicada. Belo Horizonte: Editora UFMG, 2007.

MINISTÉRIO DA INTEGRAÇÃO NACIONAL. Secretaria de Desenvolvimento do CentroOeste (2007). Plano estratégico de desenvolvimento do Centro-Oeste (2007 - 2020). Mimeografado.

MYRDAL, G. Teoria econômica e regiões subdesenvolvidas. Editora Saga, 2. ed. Rio de Janeiro, 1968.

OLIVEIRA, D.V.; MARQUES, D. F.; ROMANATTO, E.; ARRIEL, M.F. As relações do comércio interestadual do estado de Goiás em 2009. Conjuntura Econômica Goiana, Goiânia, nº 16 dez. 2010.

PASCHOAL, J. A. R. O papel das políticas públicas de incentivos e benefícios fiscais no processo de estruturação industrial de Goiás 2000 - 2008. Conjuntura Econômica Goiana, Goiânia, nº 12, dez. 2009. 
PERROUX, F. A economia do século XX. Editora Herder, Lisboa, 1967.

PIRES M. J. S.; RAMOS, P. Implicações do processo de modernização na estrutura e nas atividades agropecuárias da região centro-sul do estado de Goiás. In: SOBER - Sociedade Brasileira de Economia, Administração e Sociologia Rural, $47^{\circ}$ Congresso, Porto Alegre, 2009.

ROSSETTI, José Paschoal. Introdução à economia. 19. ed. São Paulo: Atlas, 2002

RUIZ, R. M. A nova geografia econômica: um barco com a lanterna na popa? Belo Horizonte, Cedeplar, Universidade Federal de Minas Gerais, 2003.

SOUZA, N. de J. Desenvolvimento Econômico. Editora Atlas, 4. ed., São Paulo, 1999.

TAVARES, J. M. ; PORTO JR; S. S. Desigualdades intra e inter-regionais em SC: uma análise multivariada. XI Encontro Regional de Economia - ANPEC-Sul, UFPR, 2008. Disponível em: <http://www.economiaetecnologia.ufpr.br/XI_ANPEC-

Sul/artigos_aceitos.html>. Acesso em: 05 de dez. 2010.

Recebido em 01.04.14

Aprovado em 25.11.15 
APÊNDICE

\begin{tabular}{|c|c|c|c|}
\hline Município & Grupo & Município & Grupo \\
\hline Abadia de Goiás & Grupo 1 & Itaguari & Grupo 1 \\
\hline Abadiânia & Grupo 1 & Jaraguá & Grupo 1 \\
\hline Adelândia & Grupo 1 & Jaupaci & Grupo 1 \\
\hline Águas Lindas de Goiás & Grupo 1 & Jesúpolis & Grupo 1 \\
\hline Aloândia & Grupo 1 & Lagoa Santa & Grupo 1 \\
\hline Alto Paraíso de Goiás & Grupo 1 & Mambaí & Grupo 1 \\
\hline Alvorada do Norte & Grupo 1 & Mara Rosa & Grupo 1 \\
\hline Amorinópolis & Grupo 1 & Marzagão & Grupo 1 \\
\hline Anhanguera & Grupo 1 & Monte Alegre de Goiás & Grupo 1 \\
\hline Araçu & Grupo 1 & Montividiu do Norte & Grupo 1 \\
\hline Aragarças & Grupo 1 & Morro Agudo de Goiás & Grupo 1 \\
\hline Aragoiânia & Grupo 1 & Mutunópolis & Grupo 1 \\
\hline Araguapaz & Grupo 1 & Nova América & Grupo 1 \\
\hline Baliza & Grupo 1 & Nova Iguaçu de Goiás & Grupo 1 \\
\hline Bonfinópolis & Grupo 1 & Novo Gama & Grupo 1 \\
\hline Brazabrantes & Grupo 1 & Novo Planalto & Grupo 1 \\
\hline Buriti de Goiás & Grupo 1 & Padre Bernardo & Grupo 1 \\
\hline Buritinópolis & Grupo 1 & Palmelo & Grupo 1 \\
\hline Cachoeira de Goiás & Grupo 1 & Petrolina de Goiás & Grupo 1 \\
\hline Campinaçu & Grupo 1 & Planaltina & Grupo 1 \\
\hline Campinorte & Grupo 1 & Porangatu & Grupo 1 \\
\hline Campo Limpo de Goiás & Grupo 1 & Posse & Grupo 1 \\
\hline Campos Belos & Grupo 1 & Professor Jamil & Grupo 1 \\
\hline Campos Verdes & Grupo 1 & Rio Quente & Grupo 1 \\
\hline Ceres & Grupo 1 & Sanclerlândia & Grupo 1 \\
\hline Cidade Ocidental & Grupo 1 & Santa Bárbara de Goiás & Grupo 1 \\
\hline Cocalzinho de Goiás & Grupo 1 & Santa Rita do Araguaia & Grupo 1 \\
\hline Colinas do Sul & Grupo 1 & Santa Tereza de Goiás & Grupo 1 \\
\hline Corumbá de Goiás & Grupo 1 & Santa Terezinha de Goiás & Grupo 1 \\
\hline Cristianópolis & Grupo 1 & Santo Antônio de Goiás & Grupo 1 \\
\hline Damianópolis & Grupo 1 & Santo Antônio do Descoberto & Grupo 1 \\
\hline Damolândia & Grupo 1 & São Domingos & Grupo 1 \\
\hline Davinópolis & Grupo 1 & São Francisco de Goiás & Grupo 1 \\
\hline Doverlândia & Grupo 1 & São João da Paraúna & Grupo 1 \\
\hline Faina & Grupo 1 & Simolândia & Grupo 1 \\
\hline Flores de Goiás & Grupo 1 & Sítio d'Abadia & Grupo 1 \\
\hline Goianápolis & Grupo 1 & Taquaral de Goiás & Grupo 1 \\
\hline Guapó & Grupo 1 & Teresina de Goiás & Grupo 1 \\
\hline Guaraíta & Grupo 1 & Terezópolis de Goiás & Grupo 1 \\
\hline Guarani de Goiás & Grupo 1 & Três Ranchos & Grupo 1 \\
\hline Guarinos & Grupo 1 & Trombas & Grupo 1 \\
\hline Heitoraí & Grupo 1 & Uruaçu & Grupo 1 \\
\hline Iaciara & Grupo 1 & Valparaíso de Goiás & Grupo 1 \\
\hline Iporá & Grupo 1 & Varjão & Grupo 1 \\
\hline Israelândia & Grupo 1 & Alexânia & Grupo 2 \\
\hline
\end{tabular}




\begin{tabular}{|c|c|c|c|}
\hline Município & Grupo & Município & Grupo \\
\hline Alto Horizonte & Grupo 2 & Luziânia & Grupo 3 \\
\hline Americano do Brasil & Grupo 2 & Rio Verde & Grupo 3 \\
\hline Anicuns & Grupo 2 & Senador Canedo & Grupo 3 \\
\hline Barro Alto & Grupo 2 & Acreúna & Grupo 4 \\
\hline Bela Vista de Goiás & Grupo 2 & Água Fria de Goiás & Grupo 4 \\
\hline Buriti Alegre & Grupo 2 & Água Limpa & Grupo 4 \\
\hline Cachoeira Dourada & Grupo 2 & Amaralina & Grupo 4 \\
\hline Caçu & Grupo 2 & Aparecida do Rio Doce & Grupo 4 \\
\hline Caldas Novas & Grupo 2 & Aporé & Grupo 4 \\
\hline Carmo do Rio Verde & Grupo 2 & Arenópolis & Grupo 4 \\
\hline Cavalcante & Grupo 2 & Aruanã & Grupo 4 \\
\hline Cezarina & Grupo 2 & Aurilândia & Grupo 4 \\
\hline Corumbaíba & Grupo 2 & Avelinópolis & Grupo 4 \\
\hline Crixás & Grupo 2 & Bom Jardim de Goiás & Grupo 4 \\
\hline Formoso & Grupo 2 & Bom Jesus de Goiás & Grupo 4 \\
\hline Goianésia & Grupo 2 & Bonópolis & Grupo 4 \\
\hline Goianira & Grupo 2 & Britânia & Grupo 4 \\
\hline Goiatuba & Grupo 2 & Cabeceiras & Grupo 4 \\
\hline Hidrolândia & Grupo 2 & Cachoeira Alta & Grupo 4 \\
\hline Indiara & Grupo 2 & Caiapônia & Grupo 4 \\
\hline Inhumas & Grupo 2 & Caldazinha & Grupo 4 \\
\hline Itaberaí & Grupo 2 & Campestre de Goiás & Grupo 4 \\
\hline Itapaci & Grupo 2 & Campo Alegre de Goiás & Grupo 4 \\
\hline Itauçu & Grupo 2 & Castelândia & Grupo 4 \\
\hline Minaçu & Grupo 2 & Caturaí & Grupo 4 \\
\hline Mineiros & Grupo 2 & Chapadão do Céu & Grupo 4 \\
\hline Mozarlândia & Grupo 2 & Córrego do Ouro & Grupo 4 \\
\hline Nerópolis & Grupo 2 & Cristalina & Grupo 4 \\
\hline Niquelândia & Grupo 2 & Cromínia & Grupo 4 \\
\hline Nova Veneza & Grupo 2 & Cumari & Grupo 4 \\
\hline Ouvidor & Grupo 2 & Diorama & Grupo 4 \\
\hline Palmeiras de Goiás & Grupo 2 & Edealina & Grupo 4 \\
\hline Pirenópolis & Grupo 2 & Edéia & Grupo 4 \\
\hline Pires do Rio & Grupo 2 & Estrela do Norte & Grupo 4 \\
\hline Quirinópolis & Grupo 2 & Fazenda Nova & Grupo 4 \\
\hline Rialma & Grupo 2 & Firminópolis & Grupo 4 \\
\hline Rianápolis & Grupo 2 & Formosa & Grupo 4 \\
\hline Rubiataba & Grupo 2 & Gameleira de Goiás & Grupo 4 \\
\hline Santa Fé de Goiás & Grupo 2 & Divinópolis de Goiás & Grupo 4 \\
\hline Santo Antônio da Barra & Grupo 2 & Goiandira & Grupo 4 \\
\hline São Luís de Montes Belos & Grupo 2 & Goiás & Grupo 4 \\
\hline São Simão & Grupo 2 & Gouvelândia & Grupo 4 \\
\hline Trindade & Grupo 2 & Hidrolina & Grupo 4 \\
\hline Anápolis & Grupo 3 & Inaciolândia & Grupo 4 \\
\hline Aparecida de Goiânia & Grupo 3 & Ipameri & Grupo 4 \\
\hline Catalão & Grupo 3 & Ipiranga de Goiás & Grupo 4 \\
\hline Itumbiara & Grupo 3 & Itaguaru & Grupo 4 \\
\hline Jataí & Grupo 3 & Itajá & Grupo 4 \\
\hline
\end{tabular}




\begin{tabular}{ll}
\hline Município & Grupo \\
\hline Itapirapuã & Grupo 4 \\
Itapuranga & Grupo 4 \\
Itarumã & Grupo 4 \\
Ivolândia & Grupo 4 \\
Jandaia & Grupo 4 \\
Joviânia & Grupo 4 \\
Jussara & Grupo 4 \\
Leopoldo de Bulhões & Grupo 4 \\
Mairipotaba & Grupo 4 \\
Matrinchã & Grupo 4 \\
Maurilândia & Grupo 4 \\
Mimoso de Goiás & Grupo 4 \\
Moiporá & Grupo 4 \\
Montes Claros de Goiás & Grupo 4 \\
Montividiu & Grupo 4 \\
Morrinhos & Grupo 4 \\
Mossâmedes & Grupo 4 \\
Mundo Novo & Grupo 4 \\
Nazário & Grupo 4 \\
Nova Aurora & Grupo 4 \\
Nova Crixás & Grupo 4 \\
Nova Glória & Grupo 4 \\
Nova Roma & Grupo 4 \\
Novo Brasil & Grupo 4 \\
Orizona & Grupo 4 \\
Ouro Verde de Goiás & Grupo 4 \\
Palestina de Goiás & Grupo 4 \\
Palminópolis & 4 \\
Paranaiguara &
\end{tabular}

\begin{tabular}{ll}
\hline Município & Grupo \\
\hline Paraúna & Grupo 4 \\
Perolândia & Grupo 4 \\
Pilar de Goiás & Grupo 4 \\
Piracanjuba & Grupo 4 \\
Piranhas & Grupo 4 \\
Pontalina & Grupo 4 \\
Porteirão & Grupo 4 \\
Portelândia & Grupo 4 \\
Santa Cruz de Goiás & Grupo 4 \\
Santa Helena de Goiás & Grupo 4 \\
Santa Isabel & Grupo 4 \\
Santa Rita do Novo Destino & Grupo 4 \\
Santa Rosa de Goiás & Grupo 4 \\
São João d'Aliança & Grupo 4 \\
São Luíz do Norte & Grupo 4 \\
São Miguel do Araguaia & Grupo 4 \\
São Miguel do Passa Quatro & Grupo 4 \\
São Patrício & Grupo 4 \\
Serranópolis & Grupo 4 \\
Silvânia & Grupo 4 \\
Turvânia & Grupo 4 \\
Turvelândia & Grupo 4 \\
Uirapuru & Grupo 4 \\
Uruana & Grupo 4 \\
Urutaí & Grupo 4 \\
Vianópolis & Grupo 4 \\
Vicentinópolis & Grupo 4 \\
Vila Boa & Grupo 4 \\
Vila Propício & \\
\hline & \\
\hline
\end{tabular}


ANEXO

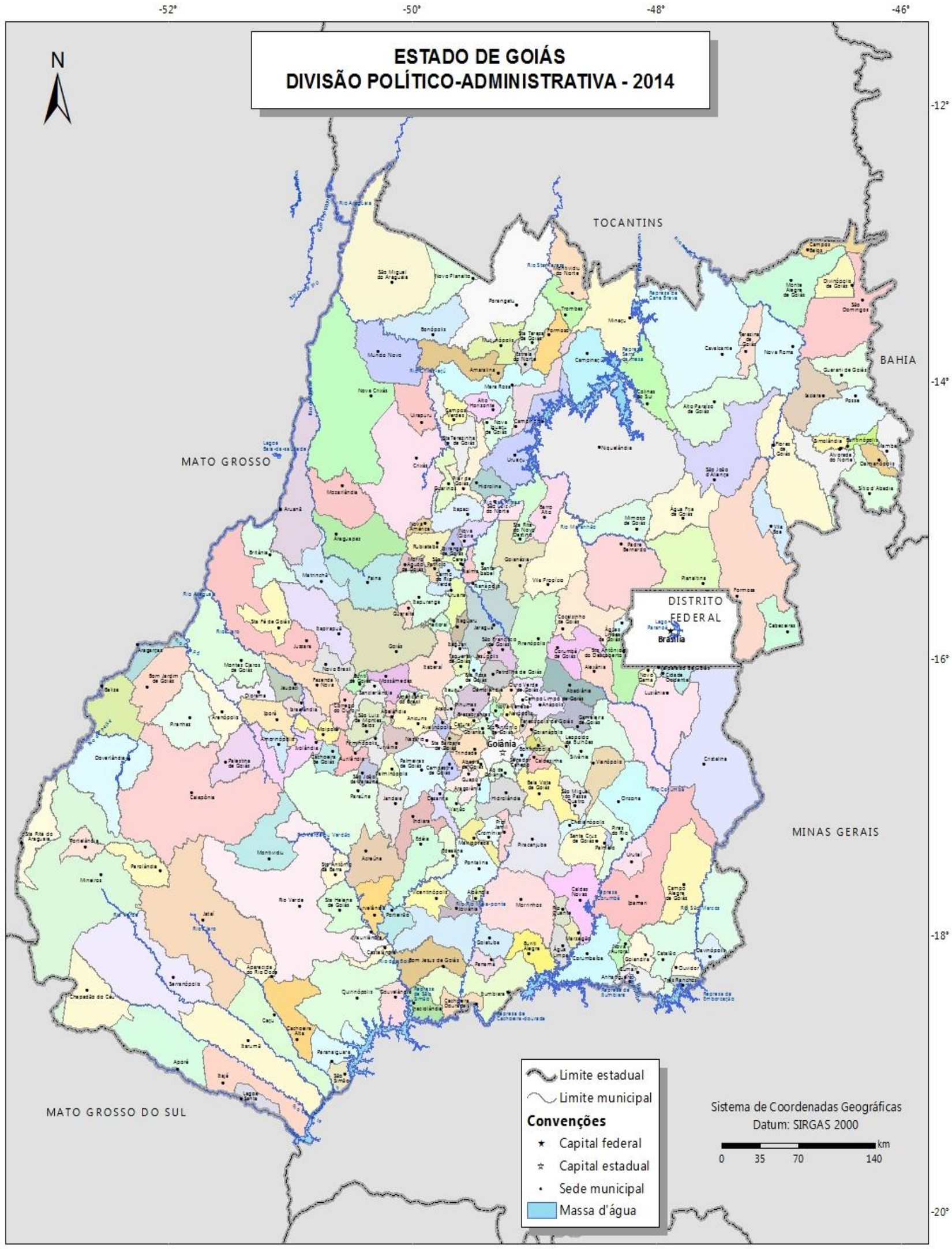

Fonte: Atlas do Estado de Goiás - Instituto Mauro Borges/Segplan/GO - 2014 